\title{
Stability of preference for saline in rats over days'
}

\author{
J. E. GRACE, ${ }^{2}$ University of Waterloo, \\ Waterloo, Ontario, Canada
}

Stability of preference for $0.5 \%$ and $2.0 \%$ concentrations of saline, separately paired with water, was assessed in rats. Over a 6-day test period, intake of hypotonic (0.5\%) saline was found to decrease while that of water increased concomitantly. Over a second 6-day test period, intake of hypertonic (2.0\%) saline decreased slightly while water intake increased slightly. A 9-day respite from saline did not alter the original pattern of water and saline in take in a subsequent retest. Possible explanations for changes in preference for saline over time ane discussed in terms of changes in salivary sodium and taste receptors, increased water need, anci alterations of the central nervous system evaluation of the gustatory input.

Several studies have shown that, for the rat, concentration of sodium chloride is one variable which determines the relative preference of this species for saline to water (Pfaffmann, 1957; Richter, 1939; Weiner \& Stellar, 1951). Rats consume increasingly more saline than water over a range of concentrations from about $0.05 \%$ (just discriminable), to about $1.0 \%$, the maximum preference occurring at about $0.9 \%$ $\mathrm{NaCl}$. With further increase in concentration, preference declines and at concentrations slightly greater than $1.0 \%$, less saline than water is consumed.

Most studies of preference for different concentrations of saline are based upon 2 days of testing at each concentration and do not describe preference stability for any concentration over longer periods of time. The purpose of this experiment was to assess preference stability over 6 days for a concentration of saline $(0.5 \%)$ preferred to water and a concentration (2.0\%) not preferred to water.

\section{METHOD}

Ninety-five, experimentally naive, male albino rats (Wistar), weighing from 280-360 g, were housed in individual cages and maintained for at least 7 days on Purina Lab Chow and tap water ad lib, prior to experimental testing. Following this maintenance period, the rats were given access ad lib to two graduated drinking bottles, one filled with distilled water and the other with hypotonic saline $(0.5 \% \mathrm{NaCl})$ for 6 consecutive days (Days 1-6) and for 1 additional day (Day 7) with only water available. Following this period, two bot tles, one containing water and the other hypertonic saline $(2.0 \% \mathrm{NaCl})$, were available for 6 consecutive days (Days 8-13), again followed by 1 day with only water available (Day 14). Every $24 \mathrm{~h}$, fluid intake was recorded and the positions of the bottles were alternated to control for position preference. Lab Chow was available ad lib throughout. Beginning on Day 24, after 9 days on tap water only, 10 of the above rats were retested by exactly the same procedure as before. All saline solutions were made with reagent-grade sodium chloride dissolved in distilled water. Concentrations are in grams of solute per $100 \mathrm{ml}$ of solution.

The results of the fluid intake measures were subjected to analysis of variance; intakes of water and $0.5 \%$ saline were analyzed separately from those of water and $2.0 \%$ saline. Individual intakes were also converted to per cent preference, i.e., $100 \mathrm{x}$ intake in $\mathrm{ml}$ of saline/intake of saline + water in $\mathrm{ml}$.

\section{RESULTS}

Mean daily intake of hypotonic saline $(0.5 \%)$ was greater than that of water over the 6-day test period (Fig. 1). Analysis of variance showed that the difference between the amounts of water and saline consumed was significant $(\mathrm{df}=1 / 94, \quad \mathrm{~F}=65.49$, $\mathrm{p}<0.005$ ). Neither water nor saline consumption was constant across days; the Fluid by Day interaction was significant (df $=2 / 188, F=107.22, p<0.005$ ). The decline in saline preference was not offset by the increase in water intake, so that the

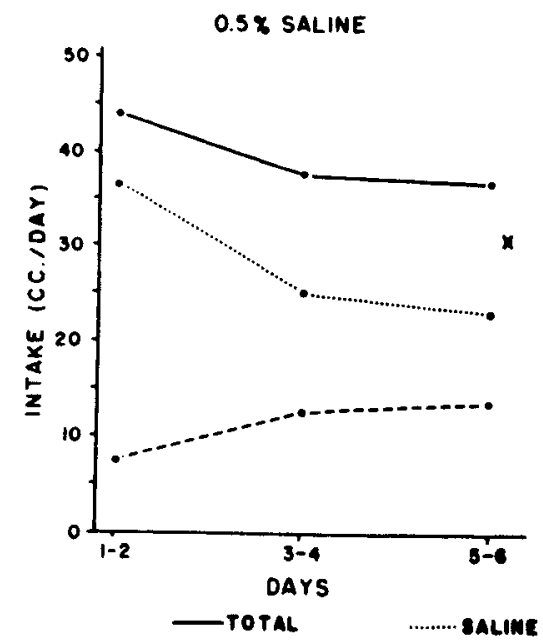

Fig. 1. Mean daily intake of water, of $0.5 \%$ or $2.0 \%$ saline, and of total fluid over 6 days. Each point is based on 2-day intakes of 95 rats. Mean 24-h intake of water on the day following each 6-day test period is denoted by $x$.

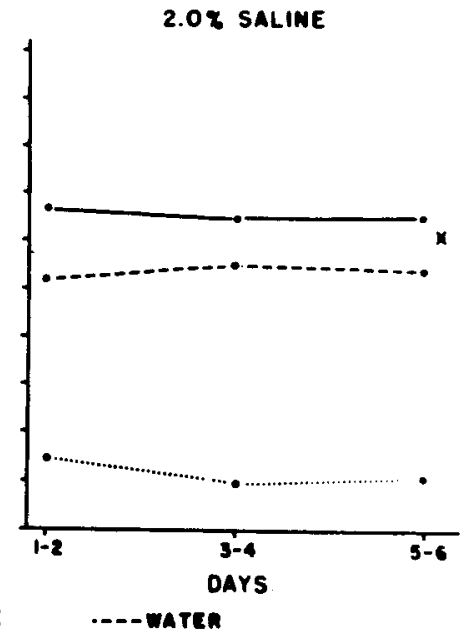

change in total fluid was significant across days $(\mathrm{df}=2 / 188, \mathrm{~F}=32.33, \mathrm{p}<0.005)$. $\mathrm{A}$ linear trend for the decrease in saline in take, across days, was significant $(\mathrm{df}=1 / 188$, $F=176.10, p<0.005$ ) as was the concomitant increase in water intake (df $=1 / 188, \quad F=35.02, \quad p<0.005)$. In addition, per cent preference for saline changed over the 6 days (Fig. 2). Assuming that, for example, $75 \%$ preference for saline is as strong a discrimination as $25 \%$ preference, then for many rats the decline in saline preference was not due to loss of the ability to discriminate saline from water. The number of rats rejecting saline, i.e., falling into the $0-25 \%$ preference range, increased over the 6 test days (Fig. 2).

Consumption of hypertonic saline, like that of hypotonic saline, showed an overall decline during the 6-day test period(Fig. 1). The decline in intake, however, was not as great as that for hypotonic saline and, in fact, a slight increase occurred from Days 3-4 to Days 5-6. Analysis of variance showed a significant difference between the amounts of water and saline consumed $(\mathrm{df}=1 / 94, \mathrm{~F}=774.43, \mathrm{p}<0.005)$ and $a$ significant Fluid by Day interaction ( $d f=2 / 188, F=20.86, p<0.005)$. A linear trend for the decrease in hypertonic saline intake was significant ( $\mathrm{df}=1 / 188$, $F=12.76, p<0.005)$. Likewise the increase in water intake over the 6 days was also significant $(\mathrm{df}=1 / 188, \quad \mathrm{~F}=6.09$, $p<0.025)$. The increase in water intake compensated the decrease in saline intake so that total fluid intake did not show a significant change over days $(\mathrm{df}=2 / 188$, $F=0.696, p>0.05$ ). Contrary to the finding for hypotonic saline, the number of

Psychon. Sci., 1969, Vol. 15 (1) 


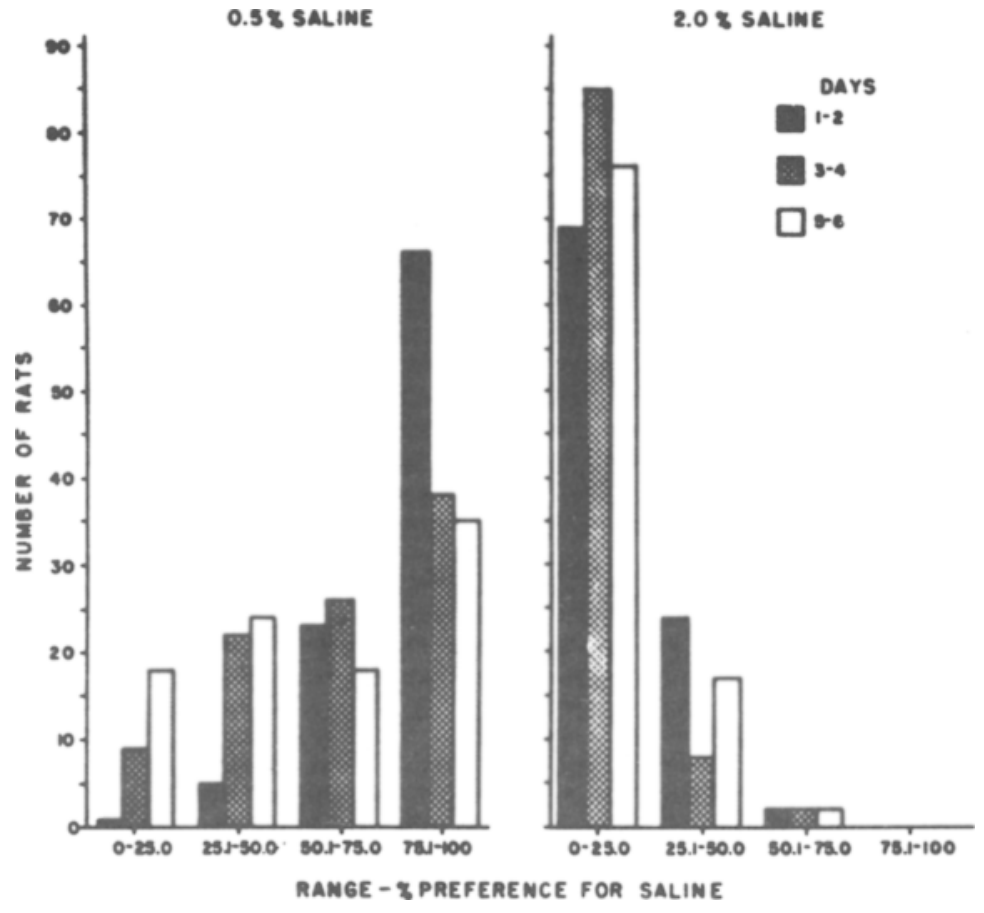

Fig. 2. Number of rats falling into four \%-preference ranges in successive days of preference testing. Per cent preference for saline is $100 \times$ total 2 -day intake of saline/total 2-day intake of saline + water. The total number of rats in each 2-day block is 95 .

rats for which intake of hypertonic saline was less than $50 \%$ of total intake, remained constant over the 6 test days (Fig. 2).

Water intakes in the single-bottle tests following water and $0.5 \%$ saline or water and $2.0 \%$ saline did not differ significantly from each other (Fig. 1). Mean water intake for the $24 \mathrm{~h}$ period following the 6 test days with water and $0.5 \%$ saline was $30.6 \mathrm{ml}$, for the 24-h period following water and hypertonic saline it was $30.5 \mathrm{ml}$. Difference scores of the two 24-h periods did not deviate significantly from chance expectations $(p=0.47)$.

Ten of the above rats, retested by the same procedure, showed the same decline in preference for hypotonic saline over days as in the initial tests. Similarly, intake of hypertonic saline differed very little from that on the initial test. Comparison of total intakes of water and saline over the 6 test days showed no significant differences ( $p>0.10$, Mann-Whitney U-Test) between initial and retest intakes for water, hypotonic saline, or hypertonic saline.

\section{DISCUSSION}

The main finding of the present investigation was that consumption of saline ad lib changes the preference of rats for this substance over time. At least three factors should be considered in accounting for changes in saline preference against water, over time. In the first place, continued consumption of sodium in excess of normal dietary allowances, might be expected to elevate plasma sodium. This, in turn, would increase the concentration of salivary sodium bathing the taste receptors and, thereby, raise the receptor threshold McBumey \& Pfaffmann (1963) have demonstrated changes in human saline taste threshold as a function of the sodium content of saliva. Reduced taste sensitivity might contribute to the decreased preference for hypotonic saline over the 6 test days and the slight increase in consumption of, i.e., reduced aversion to, hypertonic saline from the second to the third 2-day test block. Decreased sensitivity cannot, however, account for the increasing number of rats avoiding hypotonic saline during successive test days.

Secondly, it is possible that the decrease in hypotonic saline intake and concomitant increase in water intake is a function of water need induced by excessive salt ingestion. This is unlikely, particularly during the water vs $0.5 \%$ saline period, since rats are able to concentrate urine sufficiently, i.e., extract enough water, to survive on saline as highly concentrated as $1.5 \%$ when it is the only fluid available (Adolph, 1943). With both water and hypotonic saline available, there is no "cost" to the rat in choosing saline to satisfy water need. Since water intake in the $24 \cdot \mathrm{h}$ period following water and $2.0 \%$ saline did not differ significantly from that following water and
$0.5 \%$ saline, it is apparent that no water need carried over from one day to the next during the water vs $2.0 \%$ period.

Thirdly, Grace (1968) has presented evidence for two mutually antagonistic neural systems, one mediating approach to hypotonic saline and the other, aversion to more concentrated solutions. The changes in saline preference found in the present study suggest that the preference bias is altered by repeated contacts with saline. It would appear that repeated ingestion of saline lowers the threshold for activation of the aversive system. A 9-day respite from saline contact appears sufficient for the preference bias to return to its original level.

It should be emphasized that this last interpretation does not deny the possibility of peripheral changes, in the taste receptors or their bathing medium, affecting the afferent input. It does argue, however, that preference is not solely determined by the pattern of afferent input, but is also determined by the interaction of the afferent input with a central neural substrate. Grace (1968) hypothesized that changes in the body fluid and electrolyte distribution could alter the reinforcement potential of saline via interaction with the approach and aversive systems, i.e., the central substrate. The present study indicates that the afferent gustatory input from saline can also alter the bias of these antagonistic systems and, thereby, alter the preference for saline.

\section{REFERENCES}

ADOLPH, E. F. Do rats thrive when drinking sea water? American Journal of Physiology, 1943, $140,25-32$.

GRACF, J. E. Central nervous system lesions and satine intake in the rat. Physiology \& Behavior. 1968, 3, 387-393.

McBURNEY, D. H., \& PFAFFMANN, ( . Gustatory adaptation to saline and sodium chloride. Joumal of Experimental Psychology: $1963,65,523-529$.

PI AFFMANN, C. Taste mechanisms in preference behavior. American Journal of Clinical Nutrition, 1957, 5, 142-147.

RICHTER, C. P. Salt taste thresholds of normal and adrenalectomised rats. Endocrinology, $1939,24,367-371$.

WFINER, I. H. \& STELLAR, E. Salt preference in the rat determined by a single-stimulus method. Journal of Comparative \& Physiological Psychology, 1951, 44, 394-401. NOTES

1. Based upon data obtained in preparation of the author's MA and PhD theses at the U'niversity of Waterloo. Dr. G. V. Goddard was the adviser tor both theses. This research was supported hy National Research Council of Canida Grant APT 110 to Dr. Goddard. The manuscript was prepared Juring the author's tenure as a Midical Research Council of Canada Postdoctoral Fellow at the University of Western Ontario. The author is indebted to Drs. G. J. Mogenson and J. A. F. Stevenson for critical reading of the manuscript.

2. Present address: Department of Phy siology, Ihe University of Western Ontario, London, Untario, Canada. 